\title{
PENINGKATAN KEPATUHAN PENGOBATAN HIPERTENSI MELALUI KONSELING BERBASIS HUMANISTIK
}

\author{
Ivan Khidlir, Husnul Khotimah*, Bagus Supriyadi \\ Program Studi Keperawatan, Fakultas Kesehatan, Universitas Nurul Jadid, Jl.KH. Zaini Mun'im Karanganyar \\ Paiton Probolinggo, Jawa Timur, Indonesia 67291 \\ *husnulcrakers@gmail.com (+6285235430683)
}

\begin{abstract}
ABSTRAK
Orang dengan hipertensi wajib patuh dalam pengobatan hipertensi agar terhindar dari komplikasi yaitu kerusakan pada ginjal, jantung, dan otak. Tujuan penelitian ini melalui konseling berbasis humanistik adalah untuk mengetahui peningkatkan kepatuhan pengobatan hipertensi melalui konseling berbasis humanistik. Metode penelitian ini jenis kuantitatif yaitu Quasi Experimental Design bentuk Nonequivalent Control Group Design dengan 50 sample responden, 25 kelompok kontrol dan 25 kelompok perlakuan. Waktu penelitian ini dilakukan pada bulan April sampai dengan Mei tahun 2019 di posyandu lansia nuri I Desa Sumber Kemuning Kecamatan Tamanan Kabupaten Bondowoso. Penelitian eksperimen dengan uji wilcoxon signed rank testpre-test. Didapatkan pada kelompok kontrol p-value $=0,257>0,05$ dan pada kelompok perlakuan p-value $=0,001<0,05$. Uji mann-whitney nilai $\mathrm{p}$-value $=0,018$. Kesimpulan: pemberian konseling menggunakan metode berbasis humanistik yang dapat meningkatkan kepatuhan pengobatan hipertensi sehingga tidak terjadi komplikasi akibat hipertensi.
\end{abstract}

Kata kunci : hipertensi, humanistik, kepatuhan, konseling

\section{EFFECTIVENESS OF GIVING COUNSELING BASED ON HUMANISTIC AND COUNSELING WITHOUT APPROACH TOWARD OBEDIENCE OF MEDICAL HYPERTENSION}

\begin{abstract}
People with hypertension are required to comply with they hypertension treatment, in order to be saved from complication. There are kidney, hearth disease, and brain. The purpose of this study is effort to know effectiveness of giving counseling based on humanistic and counseling without approach toward obedience of medical hypertension. This research method is quantities type, namely quasi experimental design. There is non equivalent control group design with 50 sample respondence, 25 of group control and 25 of group treatment. This research do in april till may 2019 in elderly posyandu nuri I Sumber Kemuning village Tamanan sub district in Bondowoso regency. Research experimental with test of Wilcoxon signed rank test pre-test, available in group control pvalue $=0.257>0.05$ and in group experiment $p$-value $=0.001<0.05$ test of mann-whitney nilai $p$ value $=0.018$. The result is there is a differences of effectiveness that significant toward giving counseling based on humanistic with giving counseling without approach. Hopefully to the medical officially to use counseling method based on humanistic. So that can increase the obedience of medical hypertension. So the obedience of medical hypertension can increase and nothing complication caused by hypertension.
\end{abstract}

Keywords: counceling, humanistic, hypertension, obedience

\section{PENDAHULUAN}

Permasalahan penyakit tidak menular (Hipertensi) cenderung meningkat dalam beberapa dekade terakhir ini baik secara global maupun secara nasional dan telah mengancam (Subuh, 2016). Selama dua dekade terakhir ini, telah terjadi transisi epidemiologis yang signifikan (Kemenkes RI, 2016). Salah satu syarat mutlak untuk dapat mencapai efektivitas terapi dan 
meningkatkan kualitas hidup pasien adalah kepatuhan, sedangkan ketidakpatuhan pasien dalam mengonsumsi obat merupakan salah satu faktor utama penyebab kegagalan terapi (Sinuraya, 2018). Karena Peningkatan tekanan darah yang berlangsung dalam jangka waktu lama (persisten) dapat menimbulkan kerusakan pada ginjal (gagal ginjal), jantung (penyakit jantung koroner) dan otak bila tidak terdeteksi secara dini dan mendapat pengobatan yang memadai (Kemenkes, 2014).

Menurut $W H O$ memperkirakan lebih dari satu dari setiap tiga orang dewasa atau sekitar satu miliar orang di dunia menderita tekanan darah tinggi. Secara keseluruhan, WHO melaporkan Negara-negara berpendapatan tinggi punya jumlah penderita hipertensi yang lebih rendah dibandingkan Negara-negara berpendapatan rendah dan menengah yaitu yang paling banyak terdapat di Afrika, dimana hampir separuh orang dewasa mengalami hipertensi dan yang terendah di benua Amerika (Chan, 2013). Menurut Riskesdas tahun 2018, Tren PTM (Hipertensi) naik dibanding Riskesdas tahun 2013 yang didapatkan prevalensi hipertensi menurut hasil pengukuran pada penduduk umur $\geq 18$ tahun pada tahun 2013 adalah $25,8 \%$ sedangkan pada tahun 2018 adalah 34,1\% (Riskesdas, 2018). Pada sebelumnya pada Riskesdas tahun 2007 adalah $31,7 \%$ yang menunjukkan lebih kecil dibanding tahun 2018 (Riskesdas, 2007).

Menurut data Riskesdas Provinsi Jawa Timur prevalensi penyakit hipertensi mencapai 26,2\%. Prevalensi penyakit hipertensi tertinggi terdapat pada kelompok usia $\geq 75$ tahun yaitu 62,4\%. Prevalensi hipertensi di kota Surabaya mencapai 22,0\% (Hesriantica, 2017). Dari data Dinas Kesehatan Kabupaten Bondowoso pada laporan kasus PTM tahun 2018 menunjukkan jumlah kasus hipertensi sebanyak 4.696 kasus $(40,74 \%)$, dan pada
Puskesmas Tamanan menunjukkan jumlah kasus hipertensi sebanyak 453 kasus (Dinkes.Kab,2018)

Masuknya penyakit tidak menular ke dalam SDGs 2030 mengisyaratkan penyakit tidak menular harus menjadi prioritas nasional yang memerlukan penanggulangan secara lintas sector (Kemenkes, 2017). Memperhatikan PeraturanMenteri Kesehatan Republik IndonesiaNomor 25 Tahun 2016 tentang Rencana Aksi Nasional Kesehatan Lanjut Usia Tahun 2016-2019, bahwapemerintah berkewajiban untuk menjamin ketersediaan fasilitas pelayanan kesehatan dan memfasilitasi pengembangan kelompok lanjut usia serta berupaya melakukan pemeliharaan kesehatan bagi lansia (Inarti, 2018). Diantaranya posyandu lansia sebagai salah satu bentuk Upaya Kesehatan Berbasis Masyarakat (UKBM) (Sarairang, 2018). Sehingga lansia perlu mendapatkan perhatian terutama peningkatan kualitas hidup mereka agar dapat mempertahankan kesehatannya (Novianti, 2018).

Penderita hipertensi merupakan salah satu pasien yang harus diberikan konseling agar patuh terhadap pengobatan yang dijalani, dan kepatuhan menjalankan pengobatan sangat diperlukan untuk mengontrol tekanan darah serta mencegah terjadinya komplikasi dan kepatuhan pasien berpengaruh terhadap keberhasilan suatu pengobatan (Mursal, 2016). Proses konseling dapat didefinisikan sebagai sarana yang dengan seseorang membantu orang lain untuk memperjelas hidupnya situasi dan untuk memutuskan garis tindakan selanjutnya. Untuk bertindak, pasien harus dapat mengidentifikasi mereka hal-hal yang harus dia lakukan, berhenti lakukan, terus lakukan, dan terima (Hindawi, 2018).

Pasien yang diobati kronis tidak mematuhi resep obat mereka, dan banyak kurang memahami pentingnya kepatuhan dan perawatan diri. Ketidakpatuhan terhadap 
pengobatan adalah signifikan dan dapat menyebabkan peningkatan komplikasi penyakit, penurunan kualitas hidup, dan peningkatan biaya perawatan kesehatan secara keseluruhan terkait dengan komplikasi (Gangnuli, 2016). Menurut (Soenardi, 2017) bahwa mengubah perilaku dapat mempertahankan kesehatan jantung sehingga hipertensi dapat dicegah dan di kontrol. Oleh karena itu penyedia perawatan hipertensi disarankan untuk menggunakan pendekatan pendidikan "berpusat pada pasien" yang memungkinkan mereka untuk mengeksplorasi keyakinan individu dan kebutuhan pasien mereka, dan untuk menemukan landasan bersama mengenai pengobatan (Beem, 2018). Masalah yang timbul adalah: tidak mampu mempersepsi dirinya, orang lain, dan berbagai peristiwa yang terjadi di lingkungannya secara objektif, tidak terbuka terhadap semua pengalaman yang mengancam konsep dirinya, tidak mampu menggunakan semua pengalaman, tidak mampu mengembangkan dirinya kearah aktualisasi diri (Ratu, 2015).

Menurut hakikat konseling humanistik menekankan renungan filosofi tentang apa artinya menjadi manusia. Manusia memiliki kemampuan untuk berfikir secara sadar dan rasional dalam mengendalikan hasrat biologisnya, serta dalam meraih potensi maksimal mereka sehingga bertanggung jawab terhadap hidup dan kemampuan mengubah sikap dan perilaku mereka sendiri (Zulfikar, 2017).

Konseling ekstensial humanistik memeriksa kesadaran individu untuk melihat melampaui masalah mereka dan kejadian sehari-hari untuk masalah eksistensi manusia. Dari tujuan diatas dijelaskan dalam Pujosuwarno (1993:41) bahwa teknik yang bisa digunakan dalam pendekatan ini adalah: acceptance (penerimaan), respect (rasa hormat), understanding (memahami/mengerti), reasurement (menentramkan hati/ memahami), encouragement (Memberi dorongan), limited questioning (Pertanyaan terbatas), reflection (Memantulkan pertanyaan atau perasaan) (Setiawan, 2017).

Hasil analisis diatas yaitu konseling berbasis humanistik terhadap kepatuhan pengobatan maka peneliti merasa perlu dilakukan untuk mengetahui bagaimanakah dampak efektivitas konseling berbasis humanistik dan konseling tanpa pendekatan terhadap kepatuhan pengobatan hipertensi yang diprkuat oleh konsep atau proses untuk mempengaruhi perilaku kesehatan individu dan meningkatkan sistem manajemen termasuk melakukan kepatuhan terhadap pengobatan hipertensi yang dijalaninya(Jeon \& Benavente, 2016). Sehingga konseling berbasis humanistik menjadi bagian integral dari strategi kerja perawat kesehatan 'untuk mempengaruhi perilaku dalam manajemen kesehatan dan tujuan hasil kesehatan (Miller, 2011). Tujuan penelitian ini melalui konseling berbasis humanistik adalah untuk peningkatkan kepatuhan pengobatan hipertensi melalui konseling berbasis humanistik dengan jenis kuantitatif yaitu Quasi Experimental Design bentuk Nonequivalent Control Group Design. Termasuk dalam meningkatkan kepatuhan, pengetahuan, skill dan kompetensi dalam keperawatan. Konseling berbasis humanistik dapat menjadi langkah penting dalam membantu perawat untuk memberikan konseling sehingga kepatuhan pasien dalam pengobatan hipertensi meningkatdan pasien bisa terhindar dari berbagai komplikasi yang ditimbulkan.

\section{METODE}

Metode penelitian ini jenis kuantitatif yaitu Quasi Experimental Designyaitu bentuk Nonequivalent Control Group Design. Lokasi penelitian dilakukan di posyandu lansia Nuri I Desa Sumber Kemuning Kecamatan Tamanan Bondowoso, waktu penelitian dilakukan bulan Mei sampai bulan Juni pada tahun 
2019. Sampel yang digunakan pada penelitian ini 50 sampel responden $(n=25$ kelompok perlakuan, $\mathrm{n}=25$ kelompok kontrol). Hasil uji analisis wilcoxon signed rank testpre-test kelompok kontrol dan post-test pada kelompok perlakuan mengetahui perbedaan konseling berbasis humanistik dengan konseling tanpa pendekatan terhadap kepatuhan pengobatan hipertensi. Efektivitas konseling berbasis humanistik dan konseling tanpa pendekatan (independent) terhadap kepatuhan pengobatan (dependent) hipertensi diposyandu lansia Nuri I Desa Sumber Kemuning Kecamatan Tamanan Bondowoso maka pada kriteria penelitian adalah Bersedia menandatangani lembar persetujuan (Inform Consent), peserta posyandu lansia yang menderita hipertensi di posyandu lansia Nuri I Desa Sumber Kemuning Kecamatan Tamanan Kabupaten Bondowoso, peserta posyandu lansia yang masih aktif di posyandu lansia Nuri I Desa Sumber Kemuning Kecamatan Tamanan Kabupaten Bondowoso. Pengumpulan data dilakukan berdasarkan etik penelitian menunjuk pada prinsip-prinsip yang diterapkan dalam penelitian, dari proposal penelitian sampai dengan publikasi hasil penelitian. Etika penelitian bertujuan menjamin kerahasiaan identitas responden, melindungi dan menghormati hak reponden dengan mengajukan sudut pertanyaan persetujuan (informed consent) (Hidayat, 2014). Data dikumpulkan dengan lembar observasi tanda kepatuhan berupa check list pada posttest. Kemudian diberikan konseling pada kedua kelompok yaitu, menggunakan lembar observasi standar operasional prosedur (SOP) konseling berbasis humanistik pada kelompok perlakuan dan konseling tanpa pendekatan pada kelompok kontrol. Setelah dilakukan konseling yang berbeda pada kedua kelompok, kemudian dilakukan posttest menggunakan lembar observasi tanda kepatuhan berupa check list. Tanda kepatuhan yang ditemukan, kemudian dicatat untuk disesuaikan kedalam skala kepatuhan. Kemudian dilakukan uji statistik menggunakan uji wilcoxon. Kemudian setelah itu dilakukan analisa antar hasil dari kelompok perlakuan dengan konseling berbasis humanistik dan pada kelompok kontrol dengan konseling tanpa pendekatan menggunakan uji Mann-Whitney.

\section{HASIL}

Tabel 1. diketahui bahwa responden pada kelompok kontrol lebih banyak berjenis kelamin laki - laki sebanyak 13 orang (52\%) dan responden pada kelompok intervensi lebih banyak berjenis kelamin perempuan sebanyak 16 orang $(64 \%)$.

Tabel 2. hasil analisa didapatkan rata-rata kepatuhan terhadap pengobatan kelompok kontrol sebelum dilakukan konseling adalah 41,60 artinya belum patuh terhadap pengobatan (95\% CI:32,71 - 50,49), dengan standart deviasi 21,541. Kepatuhan terhadap pengobatan kelompok kontrol sebelum dilakukan konseling minimal 20 belum patuh dan tertinggi 80yang termasuk patuh. Hasil estimasi interval dapat disimpulkan bahwa 95\% diyakini bahwa rata-rata belum patuh adalah diantara 32,71 sampai dengan 50,49 artinya belum belum patuh terhadap pengobatan hipertensi.

Tabel 2. hasil analisa didapatkan rata-rata kepatuhan terhadap pengobatan kelompok kontrol setelah dilakukan konseling adalah 44,80 artinya belum patuh terhadap pengobatan (95\% CI: 35,79-53,81), dengan standart deviasi 21,817. Kepatuhan terhadap pengobatan kelompok kontrolsetelah dilakukan konseling minimal 20 belum patuh dan tertinggi 80 yang termasuk patuh. Hasil estimasi interval dapat disimpulkan bahwa 95\% diyakini bahwa rata-rata belum patuh terhadap pengobatan dengan nilai antara 35,79 sampai dengan 53,81 artinya belum belum patuh terhadap pengobatan hipertensi.

Tabel 2. hasil analisa didapatkan rata-rata kepatuhan terhadap pengobatan kelompok perlakuan sebelum dilakukan konseling 
berbasis humanistik adalah 48,80 artinya belum patuh (95\% CI: 42,03-55,57), dengan standart deviasi 16,411. Kepatuhan terhadap pengobatan kelompok perlakuan setelah dilakukan konseling berbasis humanistik minimal 20 dan tertinggi 80. Hasil estimasi interval dapat disimpulkan bahwa 95\% diyakini bahwa rata-rata adalah diantara 42,03 sampai dengan 55,57 artinya belum patuh terhadap pengobatan hipertensi.

Tabel 2. hasil analisa didapatkan rata-rata kepatuhan terhadap pengobatan kelompok perlakuan setelah dilakukan konseling berbasis humanistik adalah 83,20 artinya sudah patuh (95\% CI: 75,06- 91,34), dengan standart deviasi 19,732. Kepatuhan terhadap pengobatan kelompok perlakuan setelah dilakukan konseling berbasis humanistik minimal 40,0 dan tertinggi 100. Hasil estimasi interval dapat disimpulkan bahwa 95\% diyakini bahwa rata-rata adalah diantara 75,06 sampai dengan 91,34 artinya sudah patuh terhadap pengobatan hipertensi.

Tabel 1.

Karakteristik responden pada $(\mathrm{n}=25)$

\begin{tabular}{|c|c|c|c|c|}
\hline \multirow[t]{2}{*}{ Karakteristik responden } & \multicolumn{2}{|c|}{ Kelompok kontrol } & \multicolumn{2}{|c|}{ Kelompok intervensi } \\
\hline & $\mathrm{f}$ & $\%$ & $\mathrm{f}$ & $\%$ \\
\hline \multicolumn{5}{|l|}{ Jenis Kelamin } \\
\hline Laki - laki & 12 & 48 & 9 & 36 \\
\hline Perempuan & 13 & 52 & 16 & 64 \\
\hline \multicolumn{5}{|l|}{ Umur } \\
\hline 45 - 55 tahun & 5 & 20 & 4 & 16 \\
\hline 56 - 65 tahun & 12 & 48 & 17 & 68 \\
\hline$>65$ tahun & 8 & 32 & 4 & 16 \\
\hline \multicolumn{5}{|l|}{ Pendidikan } \\
\hline SD & 7 & 28 & 2 & 8 \\
\hline SMP & 3 & 12 & 8 & 32 \\
\hline SMA & 12 & 48 & 3 & 12 \\
\hline Sarjana/Diploma & 3 & 12 & 11 & 44 \\
\hline \multicolumn{5}{|l|}{ Pekerjaan } \\
\hline Tidak Bekerja & 7 & 28 & 6 & 24 \\
\hline Petani & 11 & 44 & 7 & 28 \\
\hline Wiraswasta & 6 & 24 & 8 & 32 \\
\hline Pensiunan & 1 & 4 & 4 & 16 \\
\hline \multicolumn{5}{|l|}{ Pendapatan } \\
\hline < Rp. 1.800 .000 & 12 & 48 & 13 & 52 \\
\hline > Rp. 1.800 .000 & 13 & 52 & 12 & 48 \\
\hline
\end{tabular}
mengalami perubahan lebih baik dalam kepatuhan pengobatan hipertensi. Di dapatkan hasil negatif sebanyak 1responden (4\%) sedangkan yang hasilpositif sebanyak 2responden $(8 \%)$ dan tetap sebanyak 22 responden (88\%). Hasil uji statistik menunjukkan nilai $P$-value $=0,257$ artinya tidak ada perubahan perilaku kepatuhan
Analisis Tabel 4. pemberian konseling berbasis humanistik terhadap kepatuhan pada responden sebelum dan sesudah tidak mengalami perubahan lebih baik dalam kepatuhan pengobatan hipertensi. Di dapatkan hasil negatif sebanyak 3responden (12\%) sedangkan yang hasilpositif sebanyak 
19responden (19\%) dan tetap sebanyak 3 responden (12\%). Hasil uji statistik menunjukkan nilai $P$-value $=0,001$ artinya ada perubahan perilaku kepatuhan pengobatan hipertensi yang signifikan pada sebelum dan sesudah dilakukan konseling berbasis humanistik.

Tabel 2 .

Karakteristik Responden kelompok kontrol $(\mathrm{n}=25)$ dan kelompok intervensi $(\mathrm{n}=25)$ terhadap kepatuhan pengobatan hipertensi

\begin{tabular}{lcccccc}
\hline \multicolumn{1}{c}{ Variabel } & N & Mean & Median & SD & Min-maks & $95 \%$ CI \\
\hline Kontrol & & & & & & \\
\hline Pre & 25 & 41,60 & 40,0 & 21,541 & $20-80$ & $32,71-50,49$ \\
\hline Post & 25 & 44.80 & 40,0 & 21,817 & $20-80$ & $35,79-53,81$ \\
\hline Perlakuan & & & & & & \\
\hline Pre & 25 & 48,80 & 40,0 & 16,411 & $20-80$ & $42,03-55,57$ \\
\hline Post & 25 & 83,20 & 80,0 & 19,732 & $40-100$ & $75,06-91,34$ \\
\hline
\end{tabular}

Tabel 3.

Perbedaan konseling tanpa pendekatan pada kelompok kontrol terhadap kepatuhan pengobatan hipertensi $(\mathrm{n}=25)$

\begin{tabular}{ccccc}
\hline & Hasil & f & $\%$ & P-value \\
\hline \multirow{2}{*}{ Konseling Tanpa Pendekatan } & Negatif & 1 & 4 & \\
\cline { 1 - 4 } & Positif & 2 & 8 & \multirow{2}{*}{0,257} \\
\cline { 1 - 4 } & Tetap & 22 & 88 & \\
\hline
\end{tabular}

Tabel 4.

Hasil analisis perbedaan konseling berbasis humanistik terhadap kepatuhan pengobatan hipertensi $(\mathrm{n}=25)$

\begin{tabular}{lcccc}
\hline & Hasil & f & $\%$ & P-value \\
\cline { 1 - 4 } Konseling Berbasis Humanistik & Negatif & 3 & 12 & \\
\cline { 1 - 4 } & Positif & 19 & 76 & 0,001 \\
\cline { 1 - 3 } & Tetap & 3 & 12 & \\
\hline
\end{tabular}

Tabel 5 .

Perbedaan efektifitas pemberian konseling berbasis humanistik pada kelompok perlakuan $(\mathrm{n}=25)$ dan konseling tanpa pendekatan pada kelompok kontrol $(\mathrm{n}=25)$

\begin{tabular}{|c|c|c|c|c|}
\hline & Kepatuhan_Post_Perlakuan & $\mathrm{N}$ & $\begin{array}{l}\text { Mean } \\
\text { Rank }\end{array}$ & $P$-value \\
\hline \multirow{3}{*}{ Kepatuhan_Post_Kontrol } & Tidak Patuh & 6 & 17,83 & \multirow{3}{*}{0,018} \\
\hline & Patuh & 19 & 11,47 & \\
\hline & Kepatuhan_Pre Perlakuan & & & \\
\hline \multirow[t]{2}{*}{ Kepatuhan Pre_Kontrol } & Tidak Patuh & 22 & 12,70 & \multirow{2}{*}{0,392} \\
\hline & Patuh & 3 & 15,17 & \\
\hline
\end{tabular}

Hasil tabel 5. analisis perbedaan efektifitas setelah dilakukan konseling berbasis humanistik pada kelompok perlakuan dan konseling pada kelompok kontrol didapatkan hasilyangpatuh 19 responden dan tidak patuh 6 responden. Hasil uji statistik diperoleh nilai $P$-value $=0,018$, karena nilai $P$-value $<0,05$ maka dapat disimpulkan ada perbedaan efektifitas pemberian konseling berbasis humanistik dengan konseling tanpa pendekatan terhadap kepatuhan pengobatan hipertensi. 


\section{PEMBAHASAN}

Berdasarkan tabel 3. dapat diketahui bahwa kelompok intervensi sebelum perlakuan, sebagian besar responden tidak patuh terhadap pengobatan hipertensi sebanyak 22 orang $(88 \%)$ dan sesudah perlakuan berbasis humanistik sebagian besar responden patuh terhadap pengobatan hipertensi sebanyak 19 orang $(76 \%)$. Hasil analisa 5.7 uji statistik untuk mengetahui perbedaan pengaruh konseling berbasis humanistik menunjukkan nilai $P$-value $=0,001$, karena nilai $P$-value $<$ 0,05 maka dapat disimpulkan bahwa ada perbedaan yang signifikan konseling berbasis humanistik terhadap kepatuhan pengobatan hipertensi.

Pada konseling berbasis humanistik yang dilakukan pada kelompok perlakuan terdiri dari tujuh langkah dalam proses pelaksanaannya. Proses tersebut terdiri dari 1.Acceptance (Penerimaan) 2.Respect (Rasa hormat) 3.Understanding (Memahami / mengerti) 4.Reasurement (Menentramkan hati / memahami) 5.Encouragement (Memberi dorongan) 6.Limitedquestioning (Pertanyaan terbatas) 7.Reflection (Memantulkan pertanyaan atau perasaan). Proses ini secara keseluruhan dilakukan bertujuan untuk memecahkan masalah yang mereka hadapi dari kesadaran klien sendiri. Tampak dari data lembar observasi klien yang menunjukkan bahwa ada peningkatan jumlah responden yang patuh setelah dilakukan konseling berbasis humanistik. Dapat disimpulkan bahwa kepatuhan meningkat secara signifikan setelah dilakukan konseling berbasis humanistik. Meskipun demikian masih ada yang belum patuh.

Hasil penelitian ini sejalan dengan pernyataan Pujosuwarno (1993:41) Konseling ekstensial humanistik memeriksa kesadaran individu untuk melihat melampaui masalah mereka dan kejadian sehari-hari untuk masalah eksistensi manusia. Hasil penelitian ini sejalan juga dengan pernyataan Setiawan (2018) Peningkatan kesadaran adalah tujuan utama konseling eksistensial, yang memungkinkan konseli untuk menemukan bahwa kemungkinan alternatif ada, di mana tidak ada yang diakui sebelumnya. Hal ini diperkuat juga oleh pernyataan Hansen (2012) dalam perluasan humanistik, ia memperingatkan perawat untuk menolak praktek-praktek yang tidak memaksimalkan kompleksitas subjektif dalam pekerjaan mereka dan dalam kapasitas klien mereka. Sebagai antitesis, saya berpendapat bahwa alat-alat ilmu tertentu dapat berguna untuk perawat, termasuk metodologi penelitian kuantitatif, penilaian diagnostik, dan praktek konseling humanisme. Hasil penelitian ini sejalan juga dengan pernyataan Lemberger (2012). Untuk mempertahankan semangat humanisme, segala bentuk konten konseling harus dipahami sebagai suatu sistem yang kompleks. Selanjutnya, interpretasi individu klien dan signifikansi adalah yang utama, bahkan jika itu menyimpang dari hasil yang dimaksud seharusnya oleh seorang perawat.

Berdasarkan tabel 4. dapat diketahui bahwa kelompok kontrol sebelum diberikan konseling tanpa pendekatan, didapatkan sebagian besar tidak patuh terhadap pengobatan hipertensi sebanyak 21 orang (84\%) dan sesudah perlakuan kontrol sebagian besar responden tetap tidak patuh sebanyak 18 orang $(72 \%)$. Hasil analisa 5.6 uji statistik untuk mengetahui perbedaan pengaruh konseling tanpa pendekatan menunjukkan nilai $P$-value $=0,257$, karena nilai $P$-value $>$ 0,05 maka dapat disimpulkan bahwa tidak ada perbedaan yang signifikan konseling tanpa pendekatan terhadap kepatuhan pengobatan hipertensi.

Pada konseling yang dilakukan terdiri dari tujuh langkah dalam proses pelaksanaannya. Proses tersebut terdiri dari 1. Merubah perilaku maladaptif, 2. Belajar mengambil keputusan, 3. Mencegah munculnya masalah baru. Proses ini secara keseluruhan merupakan proses yang dilakukan untuk meningkatkan kepatuhan dengan merubah perilaku untuk memecahkan masalah yang dihadapi klien dalam pengobatannya. Tampak dari data lembar observasi klien yang menunjukkan bahwa tidak ada peningkatan jumlah 
responden yang patuh setelah dilakukan konseling. Dapat disimpulkan bahwa kepatuhan tidak meningkat secara signifikan setelah dilakukan konseling.

Hasil penelitian ini sejalan dengan pernyataan dijelaskan oleh Setiawan (2018) yaitu proses konseling diharapkan dapat membantu konseli dalam mendapatkan wawasan baru mengenai berbagai alternatif, pemahaman, dan keterampilan baru. Yang secara umum tujuan konseling yaitu membantu konseli agar bisa mendapatkan perkembangan yang maksimal sesuai dengan potensi yang dimilikinya yaitu dengan tujuan merubah perilaku maladaptif, belajar mengambil keputusan, mencegah munculnya masalah baru. Hasil penelitian ini sejalan dengan pernyataan Bohart (2003) menekankan lembaga atau self-efficacy dari klien, menggambarkan proses konseling sebagai salah satu ciptaan bukannya memperbaiki kerusakan. Lebih khusus klien mensintesis pengalaman lama dengan cara baru untuk bergerak di luar cara-cara lama menjadi dan untuk mengaktualisasikan potensi yang belum direalisasi.

Hasil tabel 5 Hasil Analisis Perbedaan Efektifitas Setelah Pemberian Konseling Berbasis Humanistik Pada Kelompok Perlakuan Dan Konseling Tanpa Pendekatan Pada Kelompok Kontrol Terhadap Kepatuhan Pengobatan Hipertensi Di Posyandu Lansia Nuri I Desa Sumber Kemuning Kecamatan Tamanan Bondowoso didapatkan hasil yang patuh 19 responden dan tidak patuh 6 responden. Hasil uji statistik diperoleh nilai $P$ value $=0,018$ maka dapat disimpulkan ada perbedaan hasil efektifitas yang signifikan terhadap kepatuhan pengobatan hipertensi antara konseling berbasis humanistik pada kelompok perlakuan dengan konseling tanpa pendekatan pada kelompok kontrol. Penelitian pada kedua kelompok tersebut sama-sama diberikan konseling. akan tetapi jenis konseling yang digunakan berbeda yaitu pada kelompok perlakuan diberikan konseling berbasis humanistik yang terdiri dari 7 proses dan pada kelompok kontrol diberikan konseling tanpa pendekatan yang terdiri dari 3 proses saja. Tampak dari hasil uji statistik menunjukkan bahwa memang ada perbedaan efektifitas hasil antara setelah dilakukan konseling berbasis humanistik pada kelompok perlakuan yaitu dengan hasil negatif 3 responden (12\%), positif 19 responden (76\%) dan tetap 3 responden (12\%) sedangkan setelah dilakuan konseling tanpa pendekatan pada kelompok kontrol yaitu dengan hasil negatif 1 responden (4\%), positif 2 responden (8\%) dan tetap 22 responden (88\%). Hal ini terjadi hasil yang didapat pada kepatuhan pengobatan lebih baik pada konseling humanisti dari pada konseling saja.

Hasil penelitian ini sejalan dengan pernyataan Scholl, Ray \& Amoon (2014), bahwa proses dan hasil konseling dalam intervensi humansitik adalah aspek yang sangat terkait dan saling melengkapi. Hasil konseling dapat mencakup hasil klien serta hasil penelitian. Hasil klien difokuskan pada kebutuhan spesifik dari klien, hasil penelitian cenderung berfokus pada hasil yang digeneralisasikan. Ketika mempertimbangkan proses, hasil, atau penelitian, perawat humanistik berupaya untuk mengintegrasikan prinsip-prinsip humanisme ke dalam semua aspek dari praktek.

Bohart (2003) menegaskan bahwa dalam konseling humanistik, terapis, memiliki jawaban, "harus menjadi ahli dalam sebuah proses". Dalam proses konseling, perawat berusaha untuk berorientasi menjadikan klien dengan gaya interpersonal yang mengakomodasi preferensi atau proses pembangunan klien. Penelitian ini sebagian besar umur responden adalah 56 - 65 tahun 12 orang $(48 \%)$ pada kelompok kontrol dan 17 orang $(68 \%)$ pada kelompok perlakuan, yang dimungkinkan usia tersebut dapat mempengaruhi perkembangan daya tangkap dan pola pikir dalam pemberian konseling ini. Hasil penelitian ini sejalan dengan pernyataan Iqbal (2011), bahwa bertambahnya usia maka produktivitasnya ikut menurun, hal ini disebabkan keterampilan fisik akan berkurang seiring pertambahan usia. 


\section{SIMPULAN}

Ada perbedaan peningkatan hasil yang didapatkan terhadap kepatuhan pengobatanantara konseling berbasis humanistik dengan konseling tanpa pendekatan

\section{DAFTAR PUSTAKA}

Beem, L., (2014). Hypertension Patients Dutch people Medical education Blood pressure Drug therapy. Scholarly Journals, 5-6. Retrieved from

https://search.proquest.com/docview/ 1504543040 ? accountid $=13771$

Bohart, A. C., (2003). Person-centered psychotherapy and related experiential approaches. In A. S. Gurman \& S. B. Messer (Eds.), Essential psychotherapies: Theory and practice (2nd ed., pp. 107-148). New York, NY: Guilford Press.

Chan, M., (2013, April 8). WHO: 1 Miliar Orang di Dunia Alami Hipertensi. Retrieved from VOA: https://www.voaindonesia.com/a/who -1-miliar-orang-di-dunia-alamihipertensi/1636680.html

Dinas Kesehatan Bondowoso. (2018). Laporan PTM. Bondowoso: Puskesmas Tamanan.

Ganguli, A., (2016). The impact of patient support programs on adherence, clinical, humanistic, and economic patient outcomes: a targeted systematic review. Dovepress, 712. Retrieved from httpswww.ncbi.nlm.nih.govpmcarticl esPMC4854257

Hesriantica, D., (2017). Hubungan Pengetahuan Dan Riwayat Hipertensi Dengan Tindakan Pengendalian Tekanan Darah Pada Lansia. Jurnal Berkala Epidemiologi.
Intarti, W. D., (2018). Faktor-Faktor yang Mempengaruhi Pemanfaatan Posyandu. Journal of Health Studies, $111-123$.

Kemenkes. (2017, Februari senin). Peraturan Menteri Kesehatan Republik Indonesia. Retrieved from Berita Negara Republik Indonesia: www.peraturan.go.id

Kemenkes. (2018). Hasil Utama Riskesdas. Jakarta: Kemenkes Badan Penelitian dan Pengembangan Kesehatan.

Kemenkes. (2019, Maret Selasa). Untuk Indonesia Yang Lebih Sehat. Retrieved from Kemenkes: http://www.depkes.go.id/index.php?tx tKeyword=kepatuhan\&act=searchbymap\&pgnumber $=0 \&$ strucid $=1280$ \&fullcontent $=1$

Lemberger., Matthew E., 2012. A Return to the Human in Humanism: A Response to Hansen's Humanistic Vision. Jurnal of Humanistic Counseling: 164-175.

Mubarak, Wahid Iqbal., (2011). Ilmu Keperawatan Komunitas 2. Teori Dan Aplikasi Dalam Praktik Dengan Pendekatan Asuhan Keperawatan Komunitas, Gerontik Dan Keluarga. Jakarta:Sagung Seto.

Mursal., (2016). Konseling Terhadap Kepatuhan Berobat Penderita Hipertensi. Jurnal Ilmu Keperawatan, 60.

Novianti., (2018). Faktor-Faktor Yang Mempengaruhi Perilaku Lansia Dalam Mengikuti Senam Lansia. Jurnal Keperawatan Silampari, 124.

Patients; Medicine; Compliance; Health education; Health care policy; Nursing. (2018). International Journal of Hypertension, 2018, 4. Retrieved from 
https://search.proquest.com/docview/ 2010285260? accountid=13771

Puskesmas Tamanan. (2018). Pedoman Internal Profil Program Lansia Puskesmas Tamanan. bondowoso: Puskesmas Tamanan.

Ratu, B., (2015). Psikologi Humanistik (Carl Rogers). Jurnal Keguruan Ilmu Pendidikan,, 15. Retrieved from httpjurnal.untad.ac.idjurnalindex.php Kreatifarticleview33492385

RI, K., (2014). Infondatin. In P. D. RI, Hipertensi (p. 1). Jakarta Selatan: Kemenkes RI.

RI, K., (2016). Pedoman Umum Program Indonesia Sehat dengan Pendekatan Keluarga. In N. F. Moeloek, Pedoman Umum (p. 8). Jakarta: Kemenkes RI.

Riskesdas. (2007).

Saraisang, C. M., (2018). Hubungan Pelayanan Posyandu Lansia Dengan Tingkat Kepuasan Lansia Di Wilayah Kerja Puskesmas Ranomuut Kecamatan Paal Ii Kota Manado. ejournal Keperawatan, 2.

Scholl, Mark B., Ray Dee C., \& Amoon, Peggy Brady. 2014. Humanistic Counseling Process, Outcomes, and Research. Jurnal of Humanistic Counseling: 218-239.

Setiawan, M., (2018). PendekatanPendekatan Konseling Teori Dan Aplikasi. (Ngalimun, Ed.) Yogyakarta: CV Budi Utama.

Subuh, M., (2015). Rencana Aksi Program Pengendalian Penyakit dan Penyehatan Lingkungan Tahun 20152019. Jakarta: Program Pengendalian Penyakit dan Penyehatan Lingkungan.

Zulfikar., (2017). Konseling Humanistik: Sebuah Tinjauan Filosofi. Jurnal
Konseling, 149. Retrieved from httpjurnal.umk.ac.idindex.phpgusjiga ngarticleview1655 